\title{
The Effects of Several Postharvest Treatments on Shelf Life Quality of Bunch Tomatoes
}

\author{
Tuba DİLMAÇÜNAL*, Mehmet Ali KOYUNCU, Hakan AKTAŞ, Derya BAYINDIR \\ Suleyman Demirel University, Faculty of Agriculture, Department of Horticulture, 32260, \\ Isparta, Turkey; tuba.dilmacunal@gmail.com ("corresponding author)
}

\begin{abstract}
Bunch tomatoes (Lycopersicon lycopersicum L.) 'Bandita' cv. were hand-harvested at red ripe stage. The plants were grown on hanging carrying system with high wire support training in coco peat media in a plastic greenhouse located in Antalya (Turkey). Harvested fruits were divided to four groups for these treatments: (1) control-not treated; (2) tomato wax (Tomato wax is a wax formulated from $99 \%$ food grade mineral oil and $1 \%$ water); (3) Nutrient solution ( $1 \%$ potassium nitrate $+0.5 \%$ zinc sulfate $+1 \%$ calcium chloride $+0.1 \%$ boron $+0.2 \%$ copper sulfate $+0.5 \%$ ascorbic acid $+0.1 \%$ salicylic acid) and (4) Herbal oil (Herbal oil is a natural product obtained from hazelnut fruit membrane contains a high level of antioxidant). Bunches, placed in carton boxes, stored at $20^{\circ} \mathrm{C}$ temperature and $90 \pm 5 \%$ relative humidity for 16 days. Weight loss of bunches, firmness, respiration rate, ethylene production, colour, soluble solid content, $\mathrm{pH}$, titratable acidity and sensory attributes (external appearance and taste-aroma of fruits and wilting and drying of calyxes) of tomatoes were evaluated during storage. Tomato wax treatment was limited the weight loss and preserved firmness better than the others. Tomato wax, nutrient solution and herbal oil treatments were limited the respiration rate. Ethylene production of nutrient solution treated fruits showed the highest value followed by herbal oil, tomato wax and control group. The highest colour change was found in control group. The lowest soluble solid content and the highest level of acidity were found in fruits treated with tomato wax. Control, herbal oil and nutrient solution treatments were lost marketable quality after 8 days of storage. TW treatment gave the best result and provided to store bunch tomatoes at good quality for 12 days.
\end{abstract}

Keywords: herbal oil, Lycopersicon lycopersicum L., nutrient solution, storage, tomato wax

\section{Introduction}

Traditionally, tomatoes are harvested as single fruits, but the production of bunch tomatoes gains considerable added value because of their fresh appearance. However, fruit abscission and desiccation of the stems and sepals shorten the shelf-life of the bunch (Beno-Moualem et al., 2004). After harvest, unlike single tomatoes, the end of their shelf life is defined by the separation of the fruit from the bunch (Lichter et al., 2006).

Tomato fruits do not have stomata or lenticels and the fruit is enclosed within a cuticle that forms an effective barrier to water. The rachis is likely to provide a surface for evaporation from itself and from the fruit, which is expected to lead to wilting of the rachis and softening of the fruit (Dvir et al., 2009). So, there is a need to prevent desiccation of stems and sepals that causes to abscission in bunch tomatoes. In tomato, wax application is a current practice to improve its appearance and to reduce weight loss (Mejía-Torres et al., 2009).

In this study, application was done only to the rachis of the tomato fruits. There is not yet any published study on the use of some coating materials or waxes that applied only to the rachis' of tomatoes for extending shelf life of the fresh fruit. As a climacteric and perishable vegetable, tomatoes have a very short life span, usually $2-3$ weeks. So, an increase in the storage life and improvement of tomato fruit quality is really desirable (Sammi and Masud, 2007). The aim of this study is to determine the effects of some treatments on shelf life quality of bunch tomatoes during storage.

\section{Materials and methods}

\section{Plant material and treatments}

Bunch tomatoes (Lycopersicon lycopersicum L.) 'Bandita' cv. were hand-harvested at early hours of the day at ripe stage to protect the flavor intensity. The plants were grown on hanging carrying system with high wire support training in coco peat media (cocopeat, also known as coir pith, coir fibre pith, coir dust, or simply coir, is made from coconut husks, which are byproducts of other industries that use coconuts) in a plastic greenhouse located in Antalya (Turkey). Bunch tomatoes delivered to the laboratory and they were divided to four groups for these treatments: (1) control-C: not treated; (2) tomato wax-TW (tomato wax is a wax formulated from $99 \%$ food grade mineral oil and $1 \%$ water; it is liquid, its colour is amber and has no smell; the product doesn't contain any additives and any 
210

residual of heavy metals such as arsenic or lead; it controls dehydration and prevents excessive weight losses); (3) nutrient solution-NS (1\% potassium nitrate $+0.5 \%$ zinc sulfate $+1 \%$ calcium chloride $+0.1 \%$ boron $+0.2 \%$ copper sulfate $+0.5 \%$ ascorbic acid $+0.1 \%$ salicylic acid $)$ and (4) herbal oil-HO (herbal oil is a natural product obtained from hazelnut fruit membrane contains a high level of antioxidant). These four treatments were applicated by a sprayer with equal spraying dose to each of replications. Treated bunches were stored in carton boxes at $20^{\circ} \mathrm{C}$ temperature and $90 \pm 5 \%$ relative humidity conditions for 16 days. Analyses were conducted with 3 replications, with 6 bunches (each bunches consist of 6 fruits) in each replications. Weight loss of bunches, firmness, respiration rate, ethylene production, colour, soluble solid content (SSC), $\mathrm{pH}$, titretable acidity (TA) and sensory attributes (external appearance and taste-aroma of fruits and wilting and drying of calyxes) were evaluated during storage.

\section{Physical and chemical analyses}

Weight loss was expressed as the percentage of loss of weight with respect to the initial weight. Fruit firmness was determined using a digital texture machine (LF Plus Ametec Ins.) and measured via compression using a $50 \mathrm{~N}$ load cell and a stainless steel, $5.1 \mathrm{~mm}$ diameter cylindrical probe with a constant speed of $100 \mathrm{~mm} / \mathrm{min}$ at harvest date and during storage period. The maximum force $(\mathrm{N})$ generated during the probe travel was used for data analysis. Respiration rate (RR) and ethylene production (EP) of tomato fruits with calyxes were determined at the harvest date and 10 day intervals during storage. Measurements were made in S/SL of inlet in split mode with gas sampling valve with $1 \mathrm{~mL}$ gas sample by using fused silica capilar colon (GS-GASPRO, $30 \mathrm{~m}$ x $0.32 \mathrm{~mm}$ I.D.), with thermal conductivity detector (TCD) for respiration rate measurements and flame ionization detector (FID) for ethylene production measurements by Agilent GC$6890 \mathrm{~N}$ model gas chromatography (GC) and Chemstation A.09.03 [1417] software. Carrier gas flow was $1.7 \mathrm{ml} /$ min in stable flow mode. The temperature of oven, TCD and FID detectors were $40^{\circ} \mathrm{C}$ (isothermal), $250^{\circ} \mathrm{C}$ and $250^{\circ} \mathrm{C}$, respectively (Dilmaçünal, 2009). Surface colours of fruits were determined using a Minolta CR-300 colorimeter (Minolta Ramsey, NJ, USA). A white calibration plate $(\mathrm{Y}=92.3, \mathrm{x}=0.3136$ and $\mathrm{y}=0.3194)$ was used for calibration. The values were expressed by the CIE $\mathrm{L}^{\circ}$ (brightness-darkness), $\mathrm{a}^{*}\left(+\mathrm{a}^{*}\right.$ : red, $-\mathrm{a}^{*}$ : green) and $\mathrm{b}^{*}\left(+\mathrm{b}^{*}\right.$ : yellow, $-\mathrm{b}^{*}$ : blue) system and converted to $\Delta \mathrm{E}$. The soluble solid content (SSC) was measured using a digital refractometer (Atago Pocket PAL-1) and SSC was expressed as percentage of soluble solids per $100 \mathrm{~g}$ fresh weight. Titratable acidity (TA) was determined by a digital $\mathrm{pH}$ meter (Hanna Instruments HI 9231) and titrimeter (Digitrat, Isolab), and expressed as percentage of grams of citric acid equivalent per $100 \mathrm{~g}$ fresh weight and $\mathrm{pH}$ was measured by a digital $\mathrm{pH}$ meter.

\section{Sensory attributes}

A panel of 15 trained assessors were evaluated the sensory quality characteristics of fruits. Wilting and drying of calyxes were evaluated using a scale of $0-4 ; 0$ : healthy calyxes, 1-1.4: slight, 1.5-2.4: mild, 2.5-3.4: severe, 3.5-4: very severe. External appearance of fruits were evaluated using a scale of 1-9; $\leq 1-4$ : poor, $\geq 5$ : marketable, 7-8: good, 9: excellent. Taste and flavour of fruits were evaluated using a scale of 1-5; 1: very poor, 2: poor, 3: mild, 4: good, 5: excellent.

\section{Experimental design and statistical analyses}

Weight loss was analysed by ANOVA. The differences between the mean of the groups was determined by Tukey test. All analyses were performed with SPSS software package v. 18.0 for Windows by General Linear Model (GLM) univariate test.

\section{Results and discussion}

\section{Weight loss of bunches}

All treatments were showed lower weight loss values than the $\mathrm{C}$ group at the end of the storage. Weight loss of above $5 \%$ is a limiting factor for the postharvest life of many fresh fruits and vegetables. The $\mathrm{C}$ group reached to $5.44 \%$ at $8^{\text {th }}$ day of storage (Fig. 1). Javanmardi and Kubota (2006) were stored tomatoes in room temperature and found a significant greater weight loss during $7 \mathrm{~d}$ in a rate of $0.68 \%$ per day. $\mathrm{HO}(5.32 \%)$ and NS (5.55\%) treatments were above $5 \%$ at $12^{\text {th }}$ day of storage. TW treatment was successfully prevented the moisture loss and limited the weight loss (5.39\%) of fruits better than $\mathrm{HO}$ and NS treatments at the $16^{\text {th }}$ day of storage (Fig. 1). Mejía-Torres et al. (2009) were reported lower weight loss in tomatoes which were treated with different waxes as coverage and stored at room temperature. The present results agree well with these interpretations.

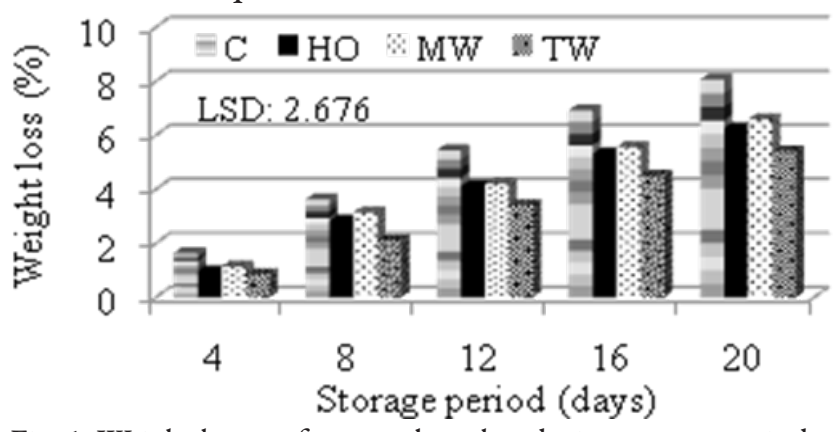

Fig. 1. Weight losses of tomato bunches during storage period

\section{Firmness}

Fruits became softer in $\mathrm{C}$ treatment $(13.53 \mathrm{~N})$ and lost $27.4 \%$ of their firmness compared to harvest date values $(18.63 \mathrm{~N}$ ), followed by NS (with $24.8 \%$ loss) and HO (with $22.0 \%$ loss) at the $16^{\text {th }}$ day of storage $(\mathrm{P}<0.05) . \mathrm{TW}$ treatment gave the best result and showed only a proportion of $12.8 \%$ decreasing at the $16^{\text {th }}$ day of storage com- 
pared to initial values (Fig. 2). It is concluded that the high water content of fruit provided high turgority and resulted with high levels of firmness. Likewise, the highest weight loss was found in $\mathrm{C}$ group while the lowest value was found in fruits treated with TW at the end of storage (Fig. 1). Direct effect of the water loss is the reduction in fruit firmness, which is measured by compressing the fruits (Dvir et al., 2009). Jeong et al. (2003) were stated a significantly delayed softening by 1-MCP and/or wax while control fruit softened rapidly and completed ripening within 7 day of storage at $20^{\circ} \mathrm{C}$. Ali et al. (2010) were found a clear softening in control fruit compared with gum arabic coated fruits at the end of storage.

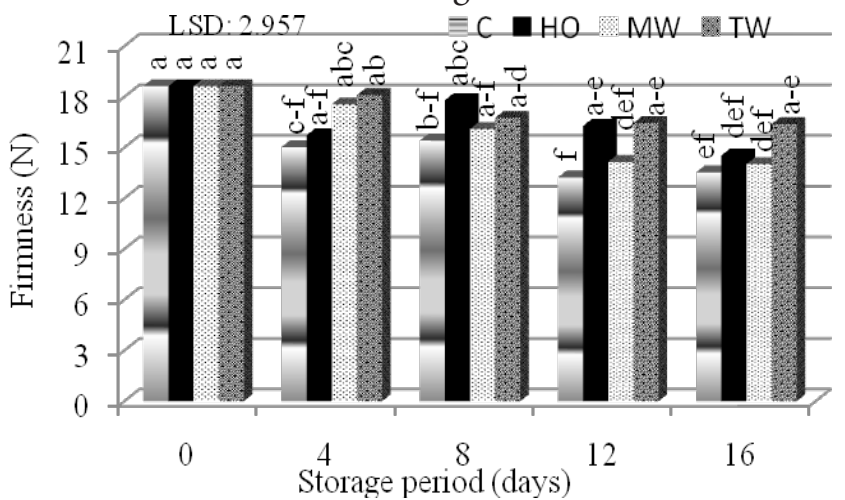

Fig. 2. Firmnesses of tomato fruits during storage period (Means with different letters are statistically significant at $\mathrm{P}<0.05$ )

\section{Respiration rate and ethylene production}

TW, NS and HO treatments were limited the respiration rate and showed closer values with each other while $\mathrm{C}$ group showed the highest value $\left(0.0372 \mathrm{ml} \mathrm{CO}_{2} / \mathrm{kg}\right.$.h $)$ at $16^{\text {th }}$ day of storage $(\mathrm{P}<0.05)$ (Fig. 3a). Ripening in tomatoes is climacteric which showed a sudden increase in ethylene production and RR (Sammi and Masud, 2007). Reduction in RR of coated tomatoes could be responsible for delaying ripening which resulted in retention of firmness during storage (Ali et al., 2010). Likewise, treated fruits were found firmer than $\mathrm{C}$ group during storage (Fig. 2). Ethylene production of NS treated fruits were higher (6.99 $\mu \mathrm{l} / \mathrm{kg} . \mathrm{h})$ than the others, followed by $\mathrm{HO}(5.39 \mu \mathrm{l} /$ kg.h), TW( $4.43 \mu \mathrm{l} / \mathrm{kg} . \mathrm{h})$ and C group $(4.14 \mu \mathrm{l} / \mathrm{kg} . \mathrm{h})$ at the $16^{\text {th }}$ day of storage (Fig. $3 \mathrm{~b}$ ).

\section{Fruit surface colour}

The effects of treatments and storage period on $\mathrm{L}^{*}$, a and $\mathrm{b}^{\mathrm{k}}$ values were statistically not significant $(\mathrm{P}<0.05)$. However, the colour change $(\Delta \mathrm{E})$ of fruits was higher in $\mathrm{C}$ group (7.63) than the others (data were not given). Lycopene, which is responsible for the red color of tomatoes, is regarded as an antioxidant with high biological activity in the body (Javanmardi and Kubota, 2006). The increasing in a values $(27.58 \%)$ and decreasing in $b^{*}$ values $(15.30 \%)$ were higher in TW treatment. This means that the fruits in TW treatment had more red surface colour than the others at the end of storage.
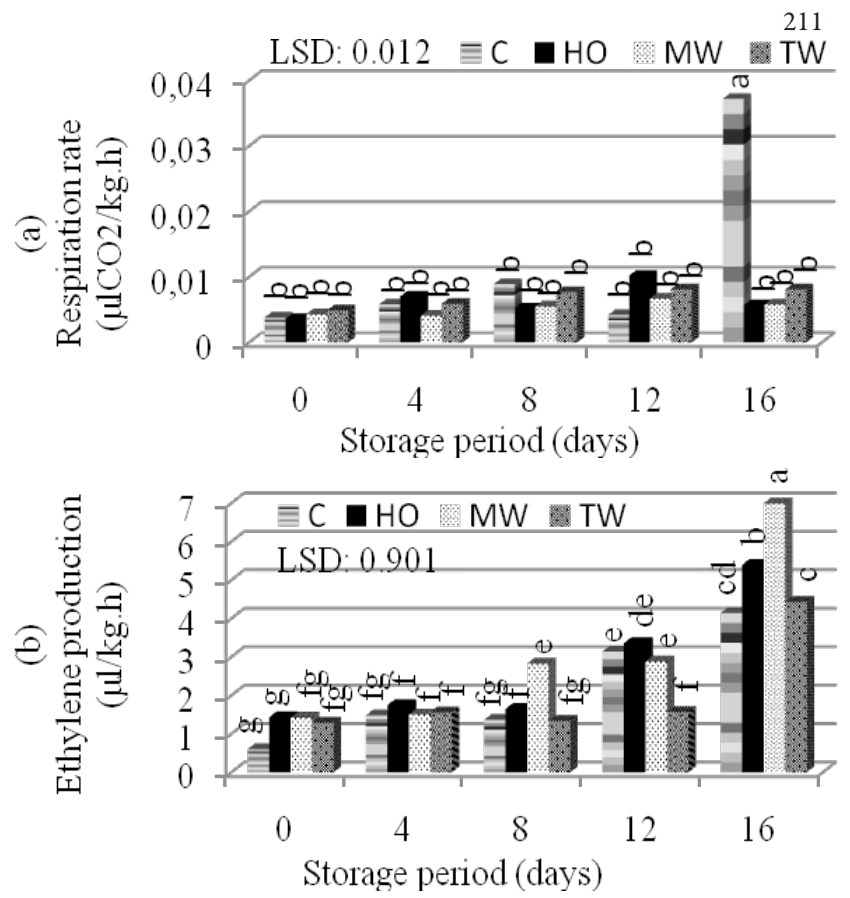

Fig. 3. (a) Respiration rate and (b) ethylene production of tomato fruits with calyxes during storage period (Means with different letters are statistically significant at $\mathrm{P}<0.05$ )

\section{Soluble solid content}

The lowest SSC content (4.58\%) was found in fruits treated with TW at the end of storage (Fig. 4). Weight loss is mainly due to the water loss and that lead to higher concentration of sugars in fruits during the storage (Bhattarai and Gautam, 2006). Decreased respiration rates also slow down the synthesis and use of metabolites resulting in lower SSC (Yaman and Bayindirli, 2002). Likewise, the lowest weight loss was found in TW treated fruits in present study (Fig. 1). The highest SSC content (5.30\%) was found in fruits treated with $\mathrm{HO}$, followed by NS (5.25\%) and $\mathrm{C}(4.88 \%)$ at the end of storage.

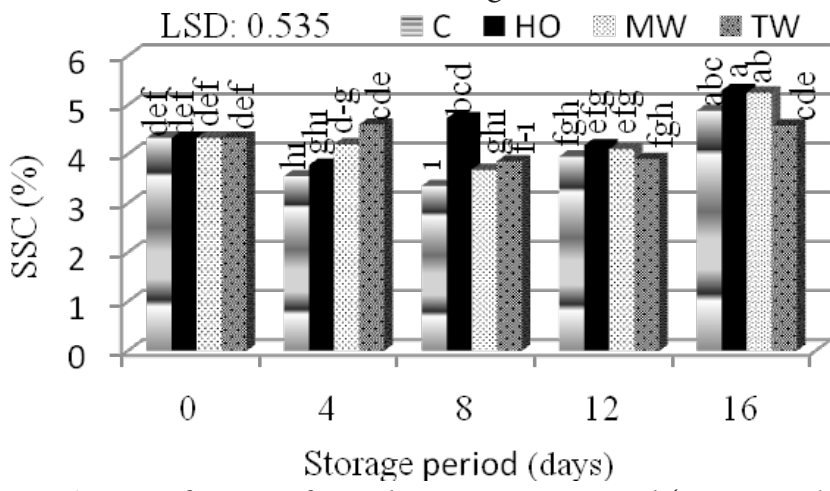

Fig. 4. SSC of tomato fruits during storage period (Means with different letters are statistically significant at $\mathrm{P}<0.05$ )

\section{Titratable acidity and $p H$ of fruits}

TA values of fruits showed a decreasing while $\mathrm{pH}$ values were increased in all treatments compared to initial values at the end of storage $(\mathrm{P}<0.05)$. Lower value $(0.21$ $\mathrm{g} / 100 \mathrm{~g}$ ) than the other treatments was found in fruits 
212

treated with NS at the $12^{\text {th }}$ day (the end of shelf life period for this treatment) of storage. The same values $(0.23$ $\mathrm{g} / 100 \mathrm{~g}$ ) were found in $\mathrm{C}$ group and $\mathrm{HO}$ treatment while the TW showed the higher level $(0.31 \mathrm{~g} / 100 \mathrm{~g})$ of acidity than the others (Fig. 5a). Higher fruit acidity is an advantage, as it causes a lower incidence of fungal infection (Getinet et al., 2008).

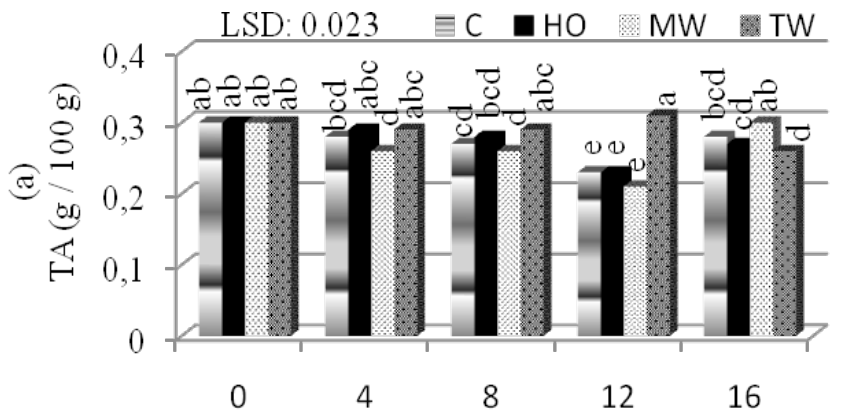

Storage period (days)

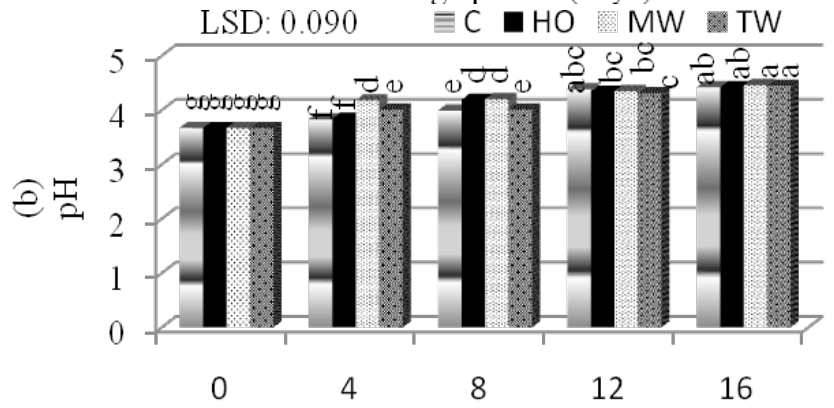

Storage period (days)

Fig. 5. (a) Titratable acidity and (b) pH of tomato fruits during storage period (Means with different letters are statistically significant at $\mathrm{P}<0.05$ )

\section{Sensory attributes}

Wilting and drying is prevented by TW treatment better than the others during storage period. The calyxes of $\mathrm{C}$ group were seemed to be more light green than the others. It is concluded that the applications made calyxes more darker because of the absorbance of the treatments by the treated calyxes (Fig. 6). External appearance (EA) and taste-aroma (TAR) scores of fruits were decreased during storage. TW treatment was found marketable (5.67 points) till to the $12^{\text {th }}$ day of storage and the TAR scores of fruits were found 3.25 points. NS and $\mathrm{HO}$ treatments were found marketable ( 5.25 and 5.17 points, respectively) till to the $8^{\text {th }}$ day of storage and after the following days fruits were found non-marketable (Fig. 7a, 7b). Likewise, the weight loses of these treatments were over the marketability limit (5\%) after the $8^{\text {th }}$ day of storage (Fig. 1). C group was seemed to be marketable at the $12^{\text {th }}$ day of storage according to EA scores (6.17 points) (Fig. 6) but the weight loss was found $5.44 \%$ at the same day of storage (Fig. 1). Therefore sensory evaluation is not only a factor that could be determine the marketability of the product by itself. So, all factors, obtained during storage, should be taken under consideration to define the shelf life of the tomato fruits.

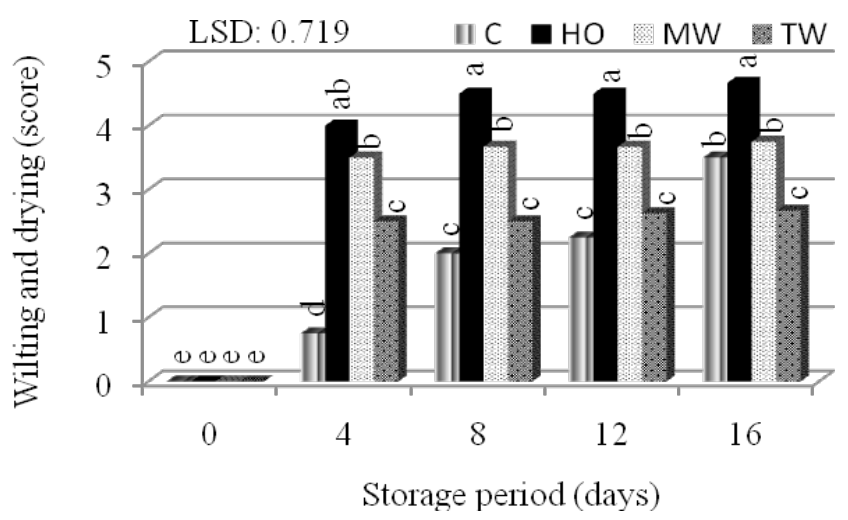

Fig. 6. Wilting and drying of tomato fruits' calyxes during storage period (Means with different letters are statistically significant at $\mathrm{P}<0.05)$
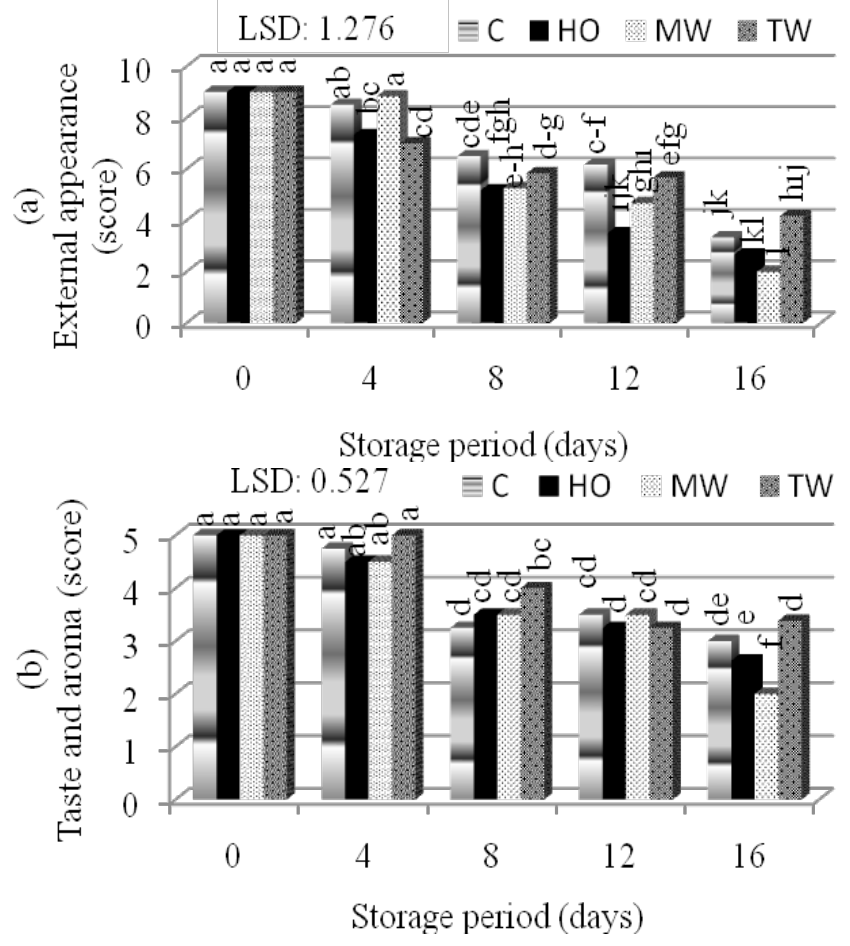

Fig. 7. (a) External appearance and (b) taste-aroma of tomato fruits during storage period (Means with different letters are statistically significant at $\mathrm{P}<0.05)$

\section{Conclusions}

In this study, tomato wax (TW) treated bunches had the good quality in terms of many attributes while control group had the poor quality during storage. TW treatment was successfully prevented the moisture loss and limited the weight loss of fruits better than $\mathrm{HO}$ and NS treatments. Fruits became softer in C group while TW treatment gave the best result. TW, NS and $\mathrm{HO}$ treatments were limited the respiration rate and showed closer values with each other while $\mathrm{C}$ group showed the highest value. Ethylene production of NS treated fruits were higher than the others, followed by $\mathrm{HO}, \mathrm{TW}$ and $\mathrm{C}$ group at the end of storage. The colour change of fruits was higher in $\mathrm{C}$ 
group than the others. The lowest SSC content was found in fruits treated with TW while the highest values were found in fruits treated with $\mathrm{HO}$, followed by NS and $\mathrm{C}$ at the end of storage. TW showed the higher level of acidity than the others. Tomato wax treatment provided to store bunches for 12 days at $20^{\circ} \mathrm{C}$ temperature in normal atmosphere conditions. Control group, herbal oil and nutrient solution treated bunches were found marketable for 8 days at the same conditions.

\section{References}

Ali A, Maqbool M, Ramachandran S, Alderson PG (2010). Gum arabic as a novel edible coating for enhancing shelflife and improving postharvest quality of tomato (Solanum lycopersicum L.) fruit. Postharv Biol Techno 58:42-47.

Beno-Moualem D, Gusev L, Dvir O, Pesis E, Meir S, Lichter A (2004). The effects of ethylene, methyl jasmonate and 1-MCP on abscission of cherry tomatoes from the bunch and expression of endo-1,4- $\beta$-glucanases. Plant Sci 167:499. 507.

Bhattarai DR, Gautam DM (2006). Effect of harvesting method and calcium on post harvest physiology of tomato. Nepal Agric Res J 7:37-41.

Dilmaçünal T. (2009). Normal and controlled atmosphere storage of some apple cultivars grown in organic and conventional farming conditions. Suleyman Demirel Univ., PhD Thesis (in Turkish).
Dvir O, Farber I, Rom M, Rachman A, Beno-Moualem D, Meir S, Lichter A (2009). Low humidity after harvest changes the abscission site in bunch cherry tomatoes. J Sci Food Agric 89:1519-1525.

Javanmardi J, Kubota C (2006). Variation of lycopene, antioxidant activity, total soluble solids and weight loss of tomato during postharvest storage. Postharv Biol Technol 41:151-155.

Jeong J, Huber DJ, Sargent SA (2003). Delay of avocado (Persea americana) fruit ripening by 1-methylcyclopropene and wax treatments. Postharv Biol Technol 28:247-257.

Lichter A, Guzev L, Dvir O, Farber I, Danshin A, Pressman E, Ganz S, Beno-Moualema D (2006). Seasonal changes in the abscission site in bunch tomatoes and differential response to 1-methylcyclopropene. Postharv Biol Technol 40:48-55.

Mejía-Torres S, Vega-García M, Valverde-Juárez J, López-Valenzuela J, Caro-Corrales J (2009). Effect of wax application on the quality, lycopene content and chilling injury of tomato fruit. J Food Quality 32:735-746.

Sammi S, Masud T (2007). Effect of different packaging systems on storage life and quality of tomato (Lycopersicon esculentum var. 'Rio Grande') during different ripening stages. Inter J Food Safety 9:37-44.

Yaman O, Bayindirli L (2002). Effects of an edible coating and cold storage on shelf-life and quality of cherries. Leben Wiss Technol 35:146-150. 